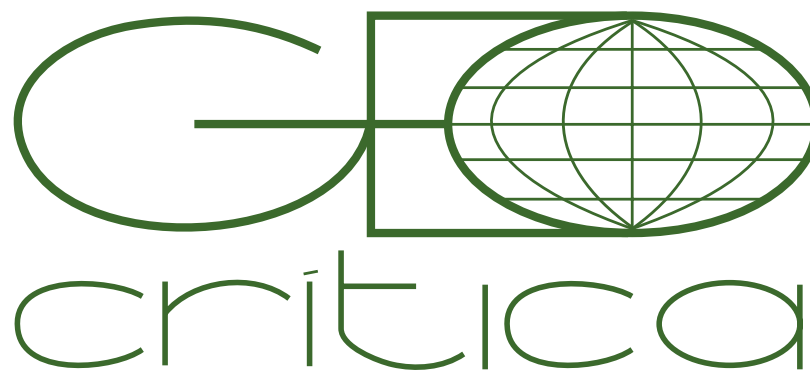

\section{Scripta Nova}

Revista Electrónica de Geografía y Ciencias Sociales Universitat de Barcelona

\title{
CARTOGRAFÍAS DE LOS DESPLAZAMIENTOS POR DESPOSESIÓN DE VIVIENDA. DESAHUCIOS Y EJECUCIONES HIPOTECARIAS EN PALMA A TRAVÉS DE SU GEOHISTORIA
}

\author{
Sònia Vives-Miró \\ so.vives@gmail.com \\ Onofre Rullan \\ orullan@uib.es \\ Jesús M. González Pérez \\ jesus.gonzalez@uib.es \\ Departament de Geografia. Universitat de les Illes Balears.
}

El presente trabajo ha contado con la ayuda de los proyectos de investigación del Plan Nacional de $I+D+I$ del Ministerio de Economía y Competitividad: "Crisis y vulnerabilidad en ciudades insulares españolas: transformaciones en los espacios de reproducción social" (CSO201568738-P) (MINECO/ FEDER) y "Nuevos Modelos De Gobierno De Las Ciudades, e intervención en los espacios urbanos en el periodo postcrisis" (CSO 2016-75236-c21-r); así como con una ayuda postdoctoral de la Vicepresidencia i Conselleria d'Innovació, Recerca i Turisme del Govern de les Illes Balears
Cartografías de los desplazamientos por desposesión de vivienda. Desahucios y ejecuciones hipotecarias en Palma a través de su geohistoria (resumen)

A partir de datos recogidos en el Servicio Común de Notificaciones y Embargos de los juzgados del partido judicial de Palma se han elaborado las cartografías de la evolución de los desahucios por impago de alquiler y las ejecuciones hipotecarias acaecidas en la ciudad entre 2003 y 2014. La desposesión de vivienda en Palma denota un comportamiento desigual, siendo mucho más intensa la concentración de ejecuciones hipotecarias en el área urbana más precarizada. No obstante, los desahucios por impago de alquiler se establecen en los espacios de gentrificación. El artículo explica este desarrollo de la geografía desigual de los desahucios a partir de las narrativas que explican la construcción geohistórica de Palma.

Palabras clave: desahucios, ejecuciones hipotecarias, desposesión de vivienda, cartografías, Palma.

Cartographies of displacements by home dispossession. Evictions and foreclosures in Palma through their geohistory (abstract)

Based on data collected in the Common Service of Notifications and Embargoes of the courts of the judicial party in Palma, cartographies of the evolution of evictions due to non-payment of rent and foreclosures occurred in the city between 2003 and 2014 have been elaborated. Dispossession of housing in Palma shows an uneven behavior, with a much more intense concentration of foreclosures in the most precarious urban area. Nonetheless, evictions due to non-payment of rent are established in gentrified spaces. The article explains this development of the unequal geography of home dispossession from the narratives that explain the geohistorical construction of Palma.

Key words: evictions, foreclosures, home dispossession, cartographies, Palma. 
El objetivo de este artículo es elaborar y analizar las cartografías de los desplazamientos por desposesión de vivienda en Palma, diferenciándolas en función de si son de desahucios por impago de alquileres o ejecuciones hipotecarias. Con ello se pretende explicar las lógicas de las geografías de los desahucios de la ciudad a partir de las narrativas que explican la construcción de su geohistoria. La desposesión de vivienda en Palma, como se manifestará a lo largo de texto, denota un comportamiento desigual, siendo mucho más intensa la concentración de ejecuciones hipotecarias en los espacios urbanos más precarizados y empobrecidos, mientras que los desahucios por impago de alquiler se localizan especialmente en los espacios de gentrificación. Un análisis que se realiza en un momento en el que, después de la crisis urbana emergida con el estallido de la burbuja inmobiliaria en 2008, parece que se están reinventando las estrategias financieras dirigiéndose esta vez especialmente a la vivienda de alquiler.

Las cartografías por desposesión de vivienda en España, hasta el momento, y debido a la gran dificultad de acceso al tipo de datos necesarios para abordar esta cuestión, han sido escasas. Aunque en el apartado siguiente se lleva a cabo una revisión bibliográfica de los estudios sobre el fenómeno, cabe señalar aquí las principales aportaciones que, más allá de la construcción estadística y cartográfica, implica el trabajo realizado. En este sentido, en primer lugar, aunque ya ha habido estudios previos que lo hayan realizado, el análisis microescalar con resolución de dirección postal es una de las principales aportaciones de este trabajo. No obstante, en segundo lugar, la que se considera la principal novedad del trabajo en relación con los precedentes es que los datos aportados permiten contrastar dos procesos hasta ahora no estudiados en paralelo: (1) las diferencias entre las lógicas espaciales de los desahucios por ejecución hipotecaria y los desahucios por impago del alquiler ya que los estudios anteriores únicamente analizaban los desahucios por ejecución hipotecaria y (2) el análisis temporal de ambos tipos de deshaucios para un período de 11 años (2003-2014).

El texto se desarrolla en cinco apartados. En primer lugar se realiza una breve revisión bibliográfica del fenómeno objeto de estudio. En segundo lugar, se explica la innovación metodológica llevada a cabo. En tercer lugar, se presentan las cartografías elaboradas y se describen sus principales rasgos. En cuarto lugar, se reflexiona sobre las causas de las geografías de estos diferentes tipos de desplazamientos en Palma a partir de la geohistoria de los diferentes espacios urbanos de la ciudad. Y, finalmente, se apuntan algunas conclusiones.

\section{La desposesión de vivienda en la literatura académica}

El fenómeno de los desahucios se ha conceptualizado en el marco de los procesos de acumulación por desposesión, en concreto en el proceso de desposesión de vivienda. A pesar de que todos los procesos de acumulación por desposesión de vivienda están impregnados de la misma lógica, sus diferentes mecanismos dan lugar también a diferentes formas de desahucios. La financiarización del entorno construi- 
do, como lógica hegemónica en los países capitalistas, articula tanto ejecuciones hipotecarias como desahucios por impago de alquiler. En cambio, los procesos de acumulación referidos a la gentrificación y turistización están más ligados a los desahucios de inquilinos. En España, las estrategias de financiarización de la vivienda, al estar centradas hasta el estallido de la burbuja en la propiedad, han conllevado las conocidas oleadas de ejecuciones hipotecarias. No obstante, a partir de 2012, la implantación de mecanismos financieros basados en las rentas del alquiler, están provocando una expansión exponencial de los desahucios de inquilinos, como ya se viene observando en Estados Unidos.

Si se lleva a cabo una revisión en la Web of Science (WoS) relacionando los conceptos de, por un lado, evictions [desahucios de inquilinos] y gentrification y, por otro, foreclosures [ejecuciones hipotecarias] y financialization se observa claramente, a partir de los artículos publicados y de las citas anuales, que se trata de fenómenos que se han empezado a trabajar en las revistas científicas a partir de 2008 y que cada vez presentan un mayor interés (ver figura 1). A finales de 2017, en WoS, había 17 artículos relacionando las ejecuciones hipotecarias y la financiarización, de los cuales 4 son trabajos referidos a espacios urbanos españoles. Por otro lado, había 58 que relacionaban los desahucios por impago de alquiler con los procesos de gentrificación, de los cuales 3 analizan ciudades españolas.

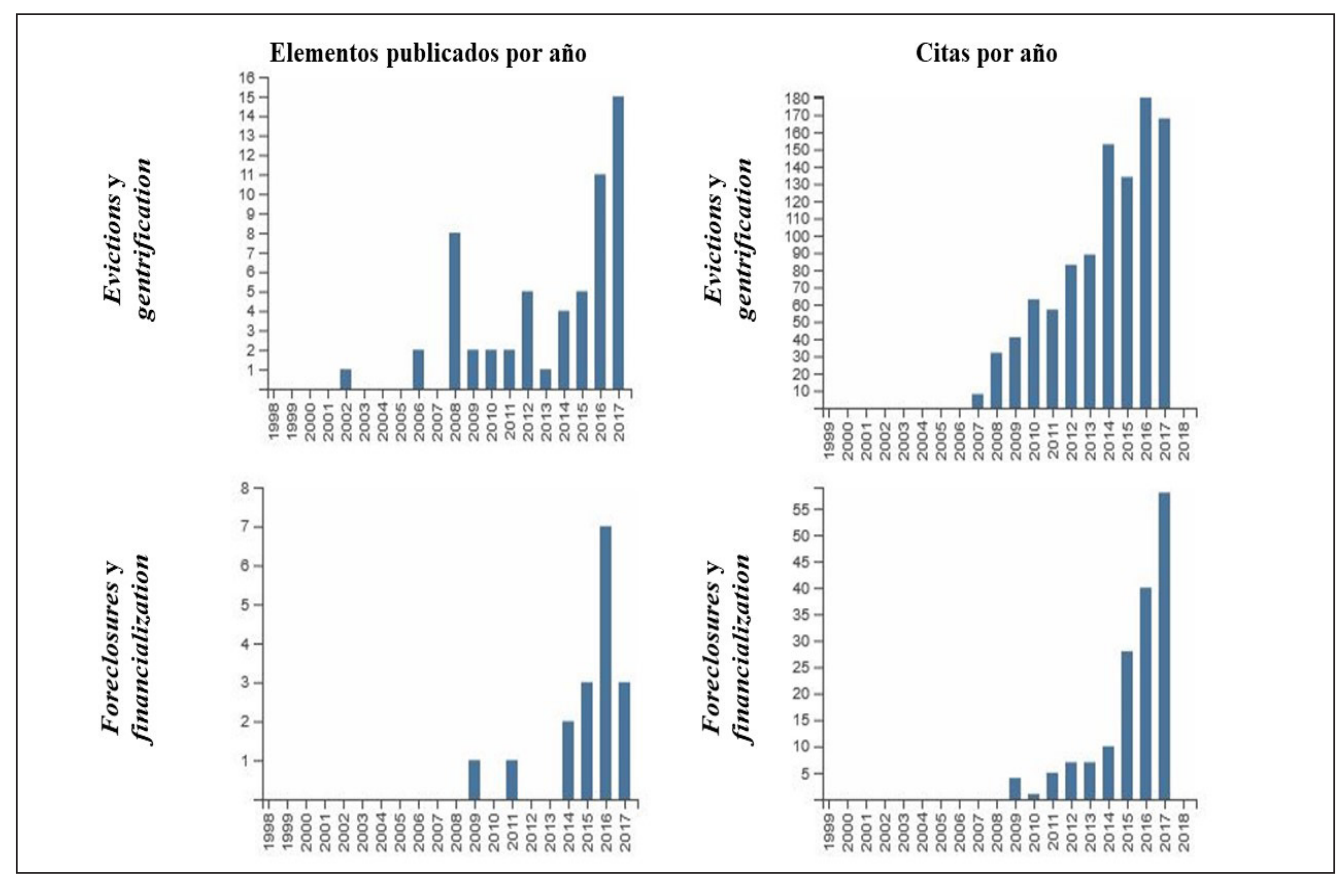

Figura 1: Artículos y citas sobre evictions/gentrification y foreclosures/financialization en WoS

Fuente: elaboración propia a partir de Web of Science, 2017

Así, los antecedentes al trabajo que se realiza en este artículo, más allá de todas las referencias teóricas clásicas sobre las lógicas urbanas de la financiarización y la gentrificación, se pueden diferenciar en varios grupos según las regiones y lugares de estudio. La bibliografía referida a los procesos de desposesión en Estados Uni- 
dos, por una parte, vincula las ejecuciones hipotecarias con la flexibilización de los mercados hipotecarios o de alto riesgo (subprime), entendiéndola como la principal causa de la crisis hipotecaria. Unas prácticas que conllevan la aparición de nuevas geografías de la deuda y del riesgo que, a su vez, se superponen a otro tipo de procesos urbanos que suceden en barrios de bajos ingresos discriminados por la raza o la desigualdad racial. Por otra parte, en cuanto a las relaciones entre gentrificación y desahucios de inquilinos, Purser argumenta, a través de un estudio en Baltimore, que los desahucios implican un "círculo de desposesión" que se reproduce material e ideológicamente. Maharawal a través de un estudio sobre las protestas de Black Lives Matter en el área de la bahía de San Francisco analiza la relación entre la vigilancia y la gentrificación como un levantamiento regional destinado a interrumpir el estado de seguridad.

Por su parte la literatura europea, aunque mucho menos numerosa, investiga las tasas de morosidad de las hipotecas y su relación con la excesiva dependencia de los mercados de vivienda determinados países europeos, sobre todo Irlanda y España. Baeten y Listerborn mediante el ejemplo de Landskrona como intensificación de los procesos de gentrificación en Escandinavia analiza el cambio acaecido al ver la vivienda asequible como un problema, en lugar de una solución así como la posible introducción de las "renovictions" en Suecia. Otros autores, mediante entrevistas sobre la actual oleada de renovación de viviendas en las ciudades suecas, analizan el desplazamiento traumático y violento que conllevó la urbanización del Million Program de los años 1960 y 1970. Estos autores sostienen que en Suecia la forma de desplazamiento (a través de la renovación) se ha convertido en una estrategia de ganancias regularizada, tanto para las empresas de vivienda públicas como privadas.

En cuanto a la literatura sobre el espacio urbano español, unos trabajos han abordado la distribución territorial de los desahucios por ejecución hipotecaria en los partidos judiciales españoles. Otros han permitido identificar las características de las viviendas desahuciadas en relación con el resto de parque de vivienda de la ciudad, sus pautas de concentración espacial y su correlación espacial con los indicadores socioeconómicos relativos a la precarización de los barrios. Otros trabajos han replicado esta misma metodología basada en las viviendas vacías propiedad de la banca para desarrollar estudios en la ciudad de Madrid y las Comunidades Autónomas de Madrid y Valenciana, respectivamente. El trabajo de Obeso trabaja a escala española para los años 2009 a 2012 y con resolución geográfica de partido judicial, relaciona a través de la mapificación el fenómeno con el paro y distingue claramente la costa mediterránea y Madrid como zonas de mayor presencia de los desahucios. Los análisis comparativos mediante una revisión de los debates sobre gentrificación ocurridos en España y América Latina durante la última década, afirman que la gentrificación en España y América Latina varía sustancialmente de los procesos en el mundo anglófono.

Finalmente, los estudios previos al presente suponen un antecedente en la explotación de la fuente presentada en este trabajo. 


\section{Metodología}

En España, la única fuente estadística sobre desahucios es la que ofrece el Consejo General del Poder Judicial (CGPJ). Los datos del CGPJ, sin embargo, sólo presentan cifras desagregadas a nivel de los 431 partidos judiciales españoles y las referidas a desahucios por impago de alquileres sólo están disponibles desde 2013. Esto significa que, para hacer un análisis del fenómeno a escala de calle o barrio, esta información es de resolución insuficiente. Para desagregar la información a escala intraurbana y diferenciar las ejecuciones hipotecarias de los desahucios de inquilinos se ha tenido que recurrir a fuentes alternativas. Para ello, se han recogido los datos de los dietarios del Servicio Común de Notificaciones y Embargos (SCNE) donde se centralizan todas las notificaciones de desahucios por impago de alquiler y las entregas de propiedad vinculadas a ejecuciones hipotecarias de los 17 juzgados de primera instancia del Partido Judicial de Palma. En estos dietarios figuran las direcciones postales de las viviendas objeto de lanzamiento por desahucio hipotecario o de desahucio por impago de alquiler. El resultado de la recopilación ha sido una base de datos donde aparecen estos lanzamientos, distinguiendo si se trata de hipotecarios o de inquilinos, la dirección completa (calle y número) y el año (de 2003 a 2014).

Hay que aclarar que los dietarios del SCNE localizan solo los lanzamientos de inquilinos o de hipotecados que, de alguna manera, se han resistido a su desalojo y que, si ha sido necesario, ha habido uso de la fuerza física. Es decir, la base de datos elaborada recoge aquellos casos que, tras el litigio, han terminado en lanzamiento. Por tanto, no se han recogido los lanzamientos que, aunque también pasaron por la sede judicial, no requieren la presencia física de la administración para consumar el desalojo. Asimismo, tampoco se han podido contemplar los llamados "desahucios silenciosos" que, al no haber generado ningún pleito judicial, no han desembocado en una resolución judicial.

De este modo, la base de datos recoge el $54 \%$ de las ejecuciones hipotecarias que se han sentenciado en el período desde 2003 hasta 2014 en todo el partido judicial de Palma. Mientras el del SCNE ha permitido localizar 3.328 ejecuciones, los datos oficiales del CGPJ contabilizan 6.213 resueltas en este periodo. Así, el 46\% restante son desahucios que no han requerido el lanzamiento del desahuciado o desahuciada.

Las cartografías presentadas de Palma y de su partido judicial, por lo tanto, deben interpretarse teniendo en cuenta que sólo identifican una parte del conflicto, la más visible, aquella que implica un lanzamiento. Mientras tanto, los desahucios sin lanzamiento y los desahucios silenciosos siguen siendo desplazamientos de los que se puede hablar, pero sin datos georeferenciados, lo que dificulta la aproximación a su problemática.

Una vez construida la base de datos con las características señaladas ha sido tratada a través de un Sistema de Información Geográfico que ha permitido cuantificar y cartografiar por interpolación de isolíneas la difusión de los dos tipos de desahu- 
cios entre 2003 y 2014 que se presentan en los mapas correspondientes a las figuras 4 a 8.

La interpretación de los resultados cuantitativos y cartográficos se ha llevado a cabo a partir del análisis del trasfondo geohistórico de los diferentes barrios y grandes piezas de la geografía urbana de la ciudad de Palma. En la figura 2 se presenta la localización de estos ámbitos que son interpretados y citados a lo largo del texto.

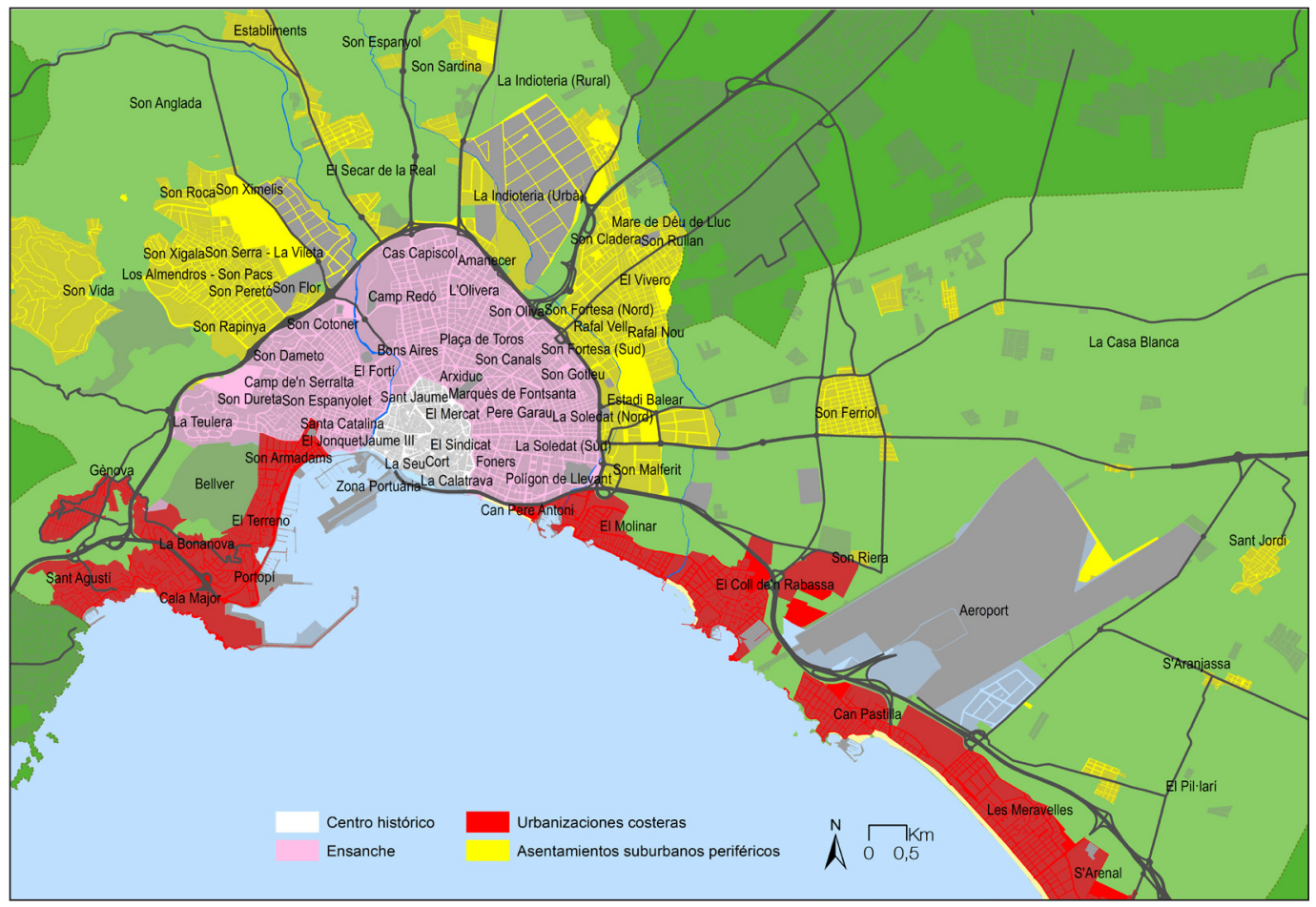

Figura 2: Áreas urbanas y barrios de Palma

La idea es que en la génesis y evolución de estos distintos ámbitos de la ciudad está la clave para la lectura de los resultados cartográficos.

\section{Cartografías de los desahucios por impago de alquiler y de las ejecu- ciones hipotecarias en Palma}

Dos resultados destacan al analizar las cartografías de los desahucios de Palma, una soslayada hasta el momento y otra más obvia y conocida.

La primera se refiere al hecho que la desposesión de vivienda que ha tenido lugar en la ciudad entre 2003 y 2014 ha sido mayoritariamente en forma de desahucios de inquilinos y, en menor medida, en forma de ejecuciones hipotecarias (ver cuadro 1 y figura 3). En este periodo, en Palma se han producido 12.479 desahucios, de los cuales el 77\% (8.601) corresponden a inquilinos y el 23\% restante a ejecuciones hipotecarias (3.878). Ese dato hasta el momento no se conocía y sólo podía intuirse pues, como ya se ha explicitado, las estadísticas de desahucios de inquilinos del CGPJ sólo están disponibles desde 2013. La lectura de este dato conduce a la consideración de dos aspectos muy vinculados al negocio inmobiliario. Por un 
lado hay que considerar que, a partir del estallido de la burbuja inmobiliaria se ha restringido la posibilidad de extraer renta urbana a través del crédito hipotecario lo que ha conducido a la implantación de mecanismos financieros que ponen la mira en el negocio del alquiler con el correspondiente corolario de subida de precios, desplazamientos y desahucios. Por otro la intensificación del negocio turístico urbano, tanto en forma de hoteles como en forma de turismo bajo diferentes fórmulas vinculadas a portales de comercialización peer to peer o P2P, como por ejemplo Airbnb, en las ciudades, ha ahondado en la misma línea: subida de precios, desplazamientos y desahucios.

Cuadro 1: Los desahucios que han implicado lanzamiento en Palma

\begin{tabular}{lcccccr}
\hline Período & $\begin{array}{c}\text { Ejecuciones } \\
\text { Hipotecarias }\end{array}$ & EH / Año & $\begin{array}{c}\text { Desahucios } \\
\text { por impago } \\
\text { de alquiler }\end{array}$ & $\begin{array}{c}\text { Desa- } \\
\text { hucios por } \\
\text { impago de } \\
\text { alquiler } / \\
\text { Año }\end{array}$ & Total & $\begin{array}{r}\text { Total/ } \\
\text { Año }\end{array}$ \\
\hline $2003-08$ & 479 & 80 & 3.399 & 567 & 3.878 & 646 \\
$2009-14$ & 2.407 & 401 & 6.194 & 1.032 & 8.601 & 1.434 \\
$2003-14$ & 2.886 & 241 & 9.593 & 799 & 12.479 & 1.040 \\
\hline
\end{tabular}

Fuente: elaboración propia

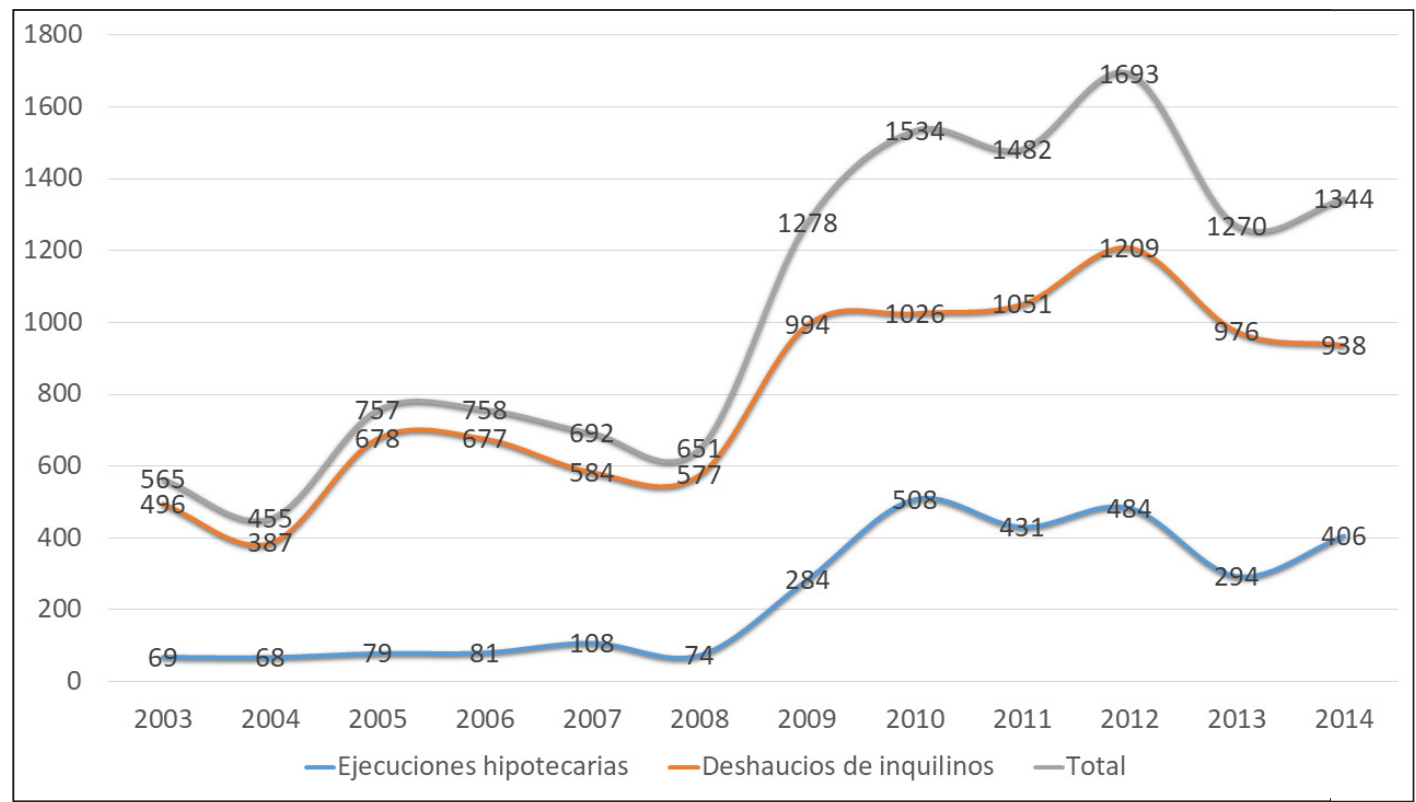

Figura 3: evolución de los desahucios en Palma (2003-2014)

Fuente: Elaboración propia a partir de SCNE

El segundo dato, el más obvio y conocido, es que el $75 \%$ de estos desahucios, un total de 9.252, se han ejecutado desde que estalló la burbuja inmobiliaria (6.771 por impago de alquiler y 2.481 ejecuciones hipotecarias). Por tanto, se puede afirmar que ambos tipos de desahucios han tenido una magnitud mucho mayor desde que 
estalló la burbuja, multiplicándose por 2,2. Si el promedio anual era de 646 desahucios por año antes de la crisis, la cifra se ha incrementado hasta los 1.434 en el período de crisis. En la figura 3 se puede constatar el efecto de las moratorias de 2012 y 2013 que contuvieron y rebajaron momentáneamente las cifras. Una contención que también se ha podido observar en los datos referidos a todos los partidos judiciales de las Islas Baleares y de España.

Sin embargo, a pesar de la evolución paralela de las cifras globales, las cartografías elaboradas a partir de la metodología explicada (figuras 4, 5 ,6 y 7) muestran que las ejecuciones hipotecarias y los desahucios por impago de alquiler presentan una geografía diferenciada.

Por un lado, la evolución anual entre 2003 y 2014 de los desahucios por impagos de alquiler (figuras 4 y 5) es en un fenómeno que se inició en el centro histórico y se expandió hacia el ensanche oriental, generalizándose a toda la ciudad a partir del estallido de la burbuja. La concentración de este tipo de desahucios empieza a ser notable desde 2009 en los barrios de Foners/Pere Garau (700 desahucios) y el Terreno (600 desahucios). A partir de 2013, emergieron otras áreas como Santa Catalina/el Camp d'en Serralta, Bons Aires, Camp Redó, els Hostalets, la Gerreria, Son Gotleu que ya dibujaban el escenario geográfico actual de desahucios de inquilinos.

Por otro lado, la expansión de las ejecuciones hipotecarias durante este período muestra una geografía opuesta a la de los desahucios de inquilinos. Si bien los desahucios de inquilinos se han ido expandiendo de forma difusa en la geografía palmesana, las ejecuciones hipotecarias lo han hecho de manera concentrada. En este sentido, las figuras 5 y 6 permiten observar como los lanzamientos de ejecuciones hipotecarias al inicio del período analizado se localizaron en diferentes núcleos aislados unos de otros, destacando el barrio de Corea. Este fenómeno se fue expandiendo, hasta que explotó a partir de 2010. Sin embargo, la cima de Son Gotleu a partir de 2006 ya contaba con más de 300 desahucios. Desde que estalló la crisis, la concentración de las ejecuciones hipotecarias en Son Gotleu se ha intensificado, extendiéndose hacia los barrios de Pere Garau/Foners. Toda esta área supera con cierta diferencia otros barrios con una alta concentración de lanzamientos como Camp Redó (Corea), el Camp d'en Serralta, Son Ximelis o Cala Major.

En resumen, como se puede apreciar en los mapas, los desahucios de inquilinos, más importantes cuantitativamente, siguen una espacialización difusa y se sitúan, sobre todo, en los barrios de clase media o media alta donde la gentrificación, en sus diferentes grados y etapas, se hace más evidente. En concreto, en Pere Garau/Foners, Camp d'en Serralta/Santa Catalina, la Gerreria, Camp Redó, Buenos Aires y el Terreno. Mientras tanto, las ejecuciones hipotecarias muestran una clara concentración espacial y se sitúan mayoritariamente en los barrios de clase media o media baja. Se concentran lejos del centro histórico, en la parte oriental de la ciudad, especialmente en Son Gotleu, es decir, en los barrios más empobrecidos. 


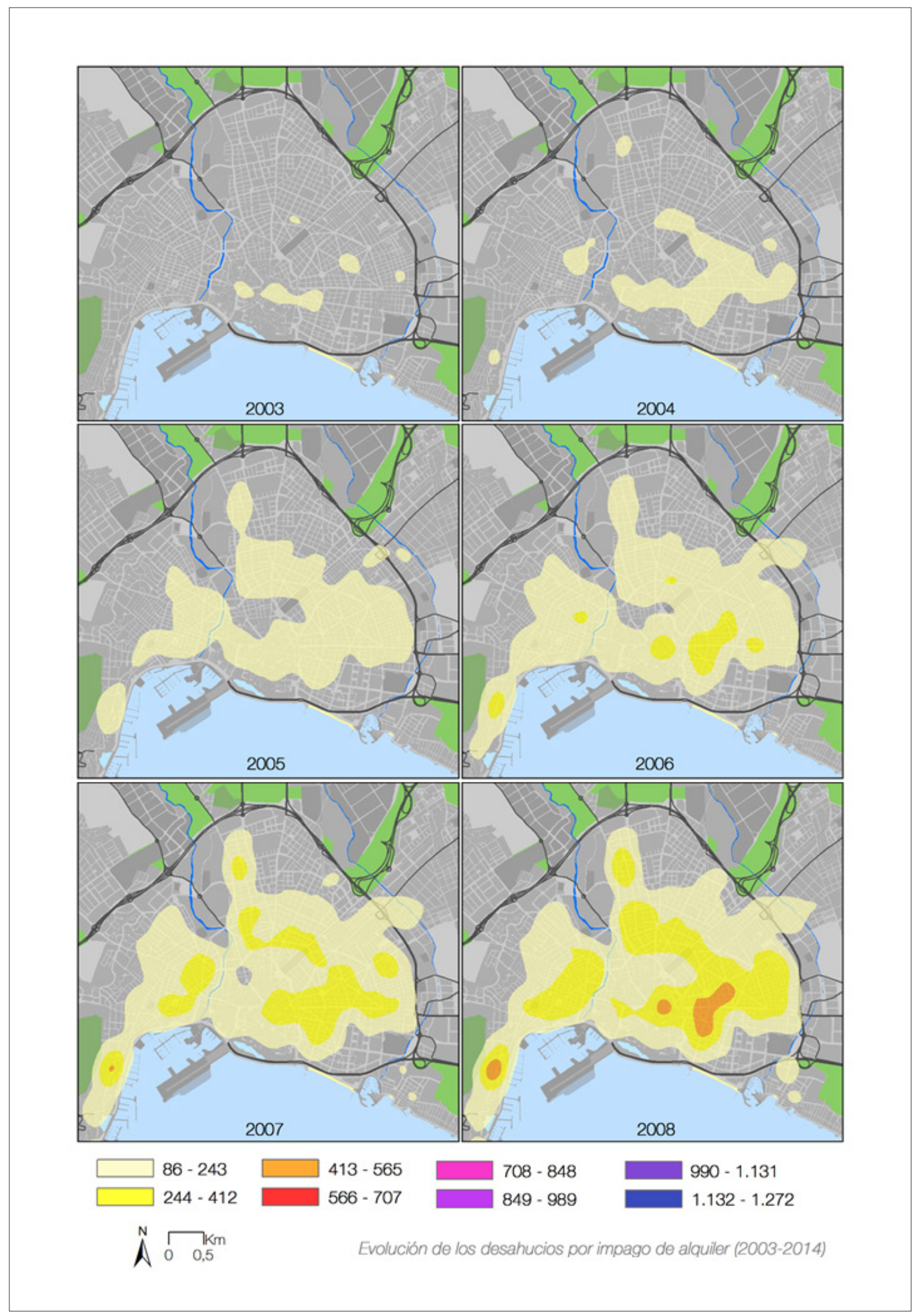

Figura 4: evolución de los desahucios por impago de alquiler en el periodo de burbuja (20032008)

Fuente: elaboración propia 


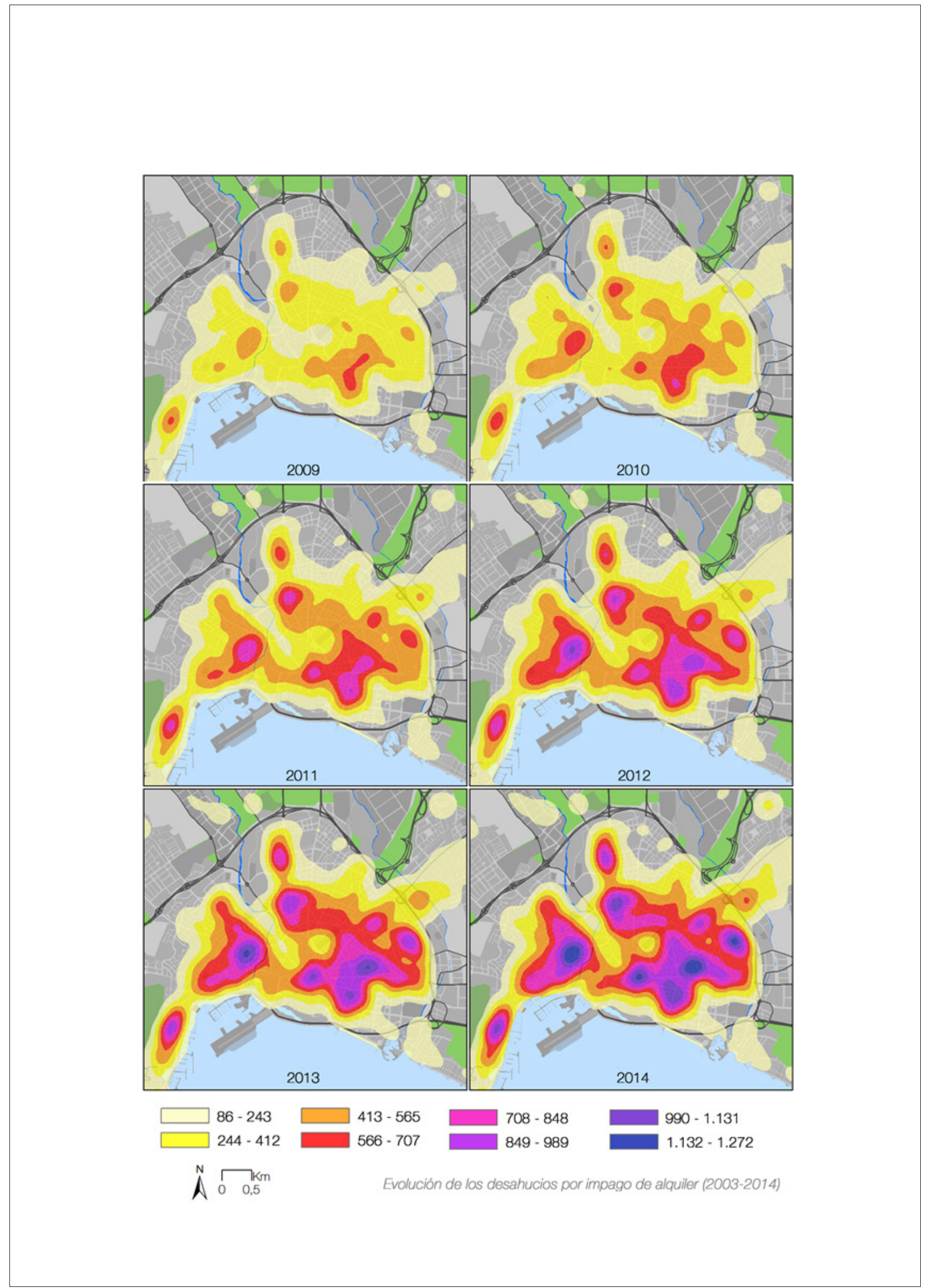

Figura 5: evolución de los desahucios por impago de alquiler en el periodo de crisis (2009-2014) Fuente: elaboración propia 


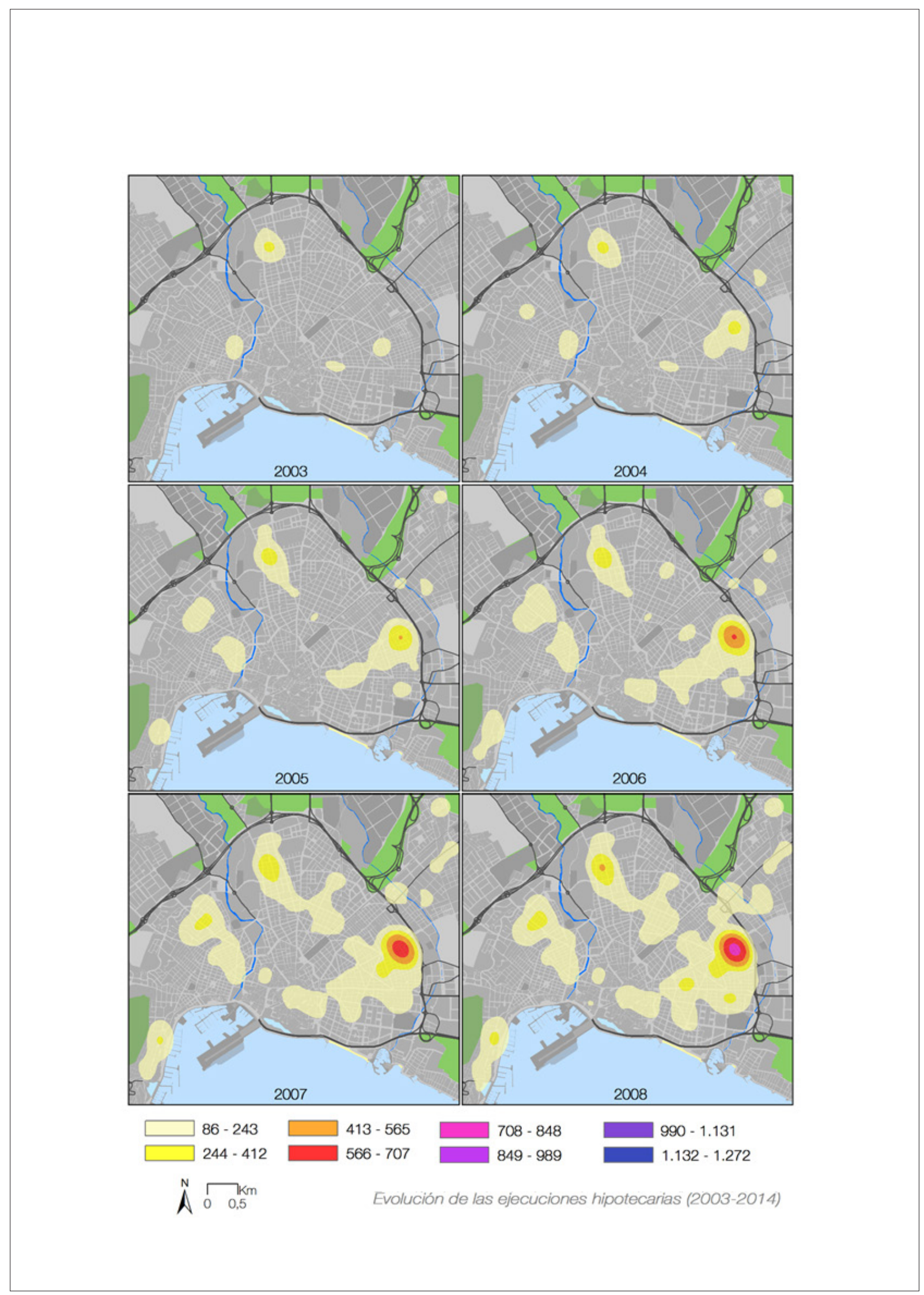

Figura 6: evolución de las ejecuciones hipotecarias en el periodo de burbuja (2003-2008) Fuente: elaboración propia 


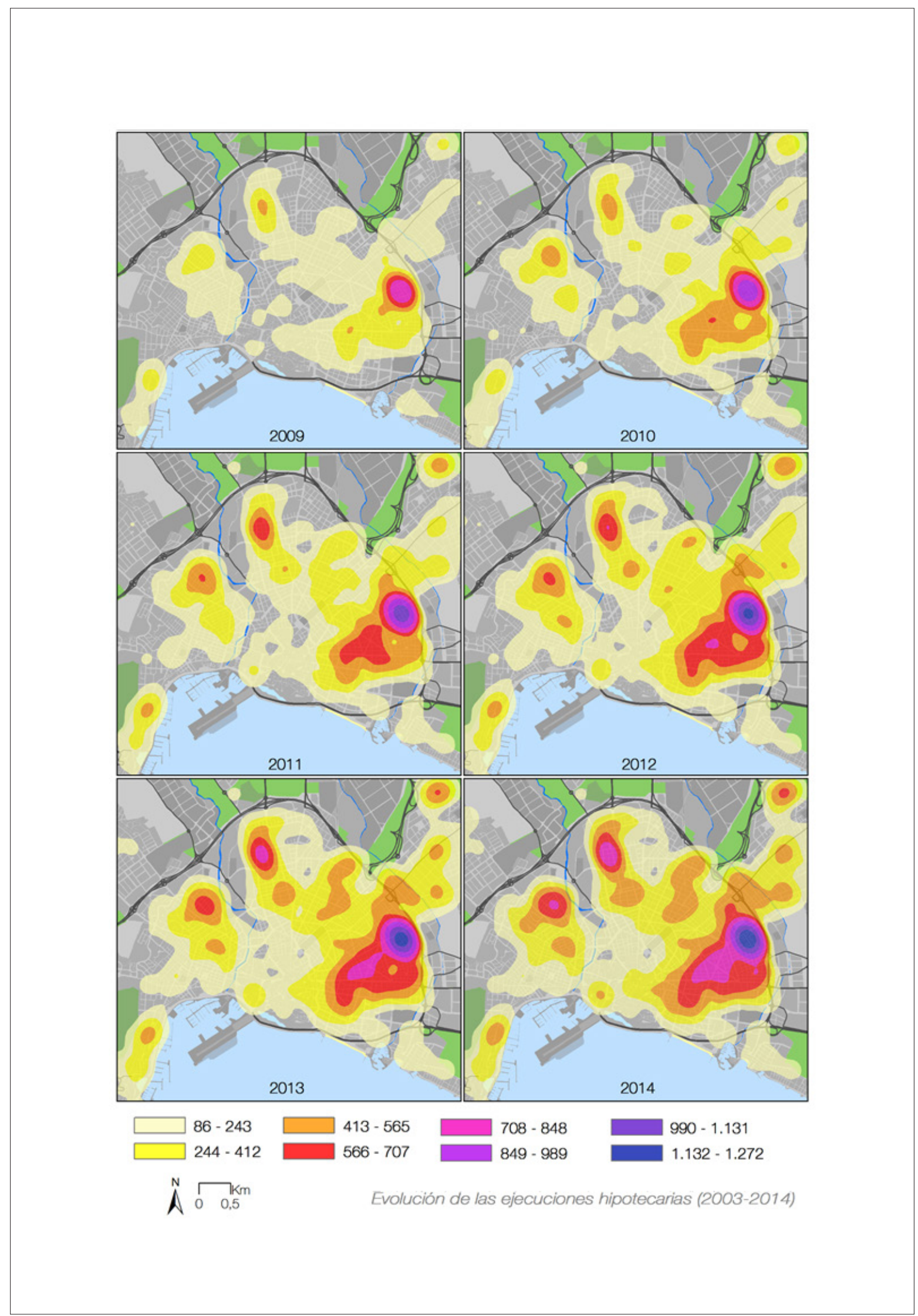

Figura 7: evolución de las ejecuciones hipotecarias en el periodo de crisis (2009-2014) Fuente: elaboración propia 


\section{La geografía de los desahucios en Palma a través de su geohistoria}

Más allá de las cifras generales y de su evolución espaciotemporal, en esta parte del texto se pretenden analizar el fondo geohistórico que ha condicionado la dinámica que ha conducido a la distribución geográfica del fenómeno que describen los mapas de la serie 2003-2014. De la observación de las cartografías elaboradas se podría deducir que los lanzamientos de desahuciados han seguido una pauta más o menos isotrópica, especialmente si se observa la cartografía que acumula los desahucios por impago de alquiler. Sin embargo, no es así, la distribución geográfica de los desahucios responde a pautas geohistóricas, económicas y sociales que, en último extremo, explican el mapa. El espacio geográfico en general y el urbano en particular es una construcción social y política que no se despliega sobre la isotropía, lo hace sobre condicionantes naturales y sociales que a la vez son actores que generan atracciones, repulsiones y algunas, pocas, indiferencias.

Para analizar a fondo a que responde la espacialización de los desahucios, lo primero que hay que explicar son las características básicas que presenta este constructo socio-espacial que es llamado Palma y sobre el que se está acuñando la Marca Palma. Vale la pena detenerse a pensar en ello, ya que es sobre y a partir de él donde se ha materializado la geografía de los desahucios.

En un esquema sencillo se puede convenir que Palma está compuesta por cuatro grandes tipos de piezas o áreas urbanas formales sobre las que se asientan diferentes formas sociales: el centro histórico, el ensanche, los asentamientos suburbanos periféricos y las urbanizaciones costeras (figura 2). Hay que insistir, hay poca correlación entre estas formas más genéricas y las diferentes sociedades que las habitan; continente formal y contenido social no siempre se corresponden.

\section{El centro histórico}

El centro histórico es el centenar largo de hectáreas que, hasta hace relativamente poco, se consideraba genuinamente Palma, hasta el punto de que, desde el ensanche, se podía "ir a Palma" cuando se cruzaban las avenidas que discurren por encima de lo que fue la muralla renacentista no costera.

En el centro histórico de Palma se concentra la mayor densidad patrimonial de Baleares fruto de una historia que se remonta a la Mallorca musulmana (903-1229). Por ello, esta parte de la ciudad es una de las más atractivas, revalorizadas y deseadas por los inversores inmobiliarios del norte y centro de Europa.

Al ser este recinto toda la ciudad hasta principios del siglo XX, en su interior se concentraban todos los estamentos y clases sociales. Esta abigarrada y diversa realidad social es la que describe Eusebio Estada, a finales del siglo XIX, en su arenga a favor del derribo de las murallas y la planificación del ensanche. En su estudio constataba como en las 100 hectáreas de la ciudad de intramuros convivían secciones que iban de los 218 a los 833 habitantes/hectárea. Palma entonces era una ciudad donde las formas precapitalistas estaban siendo transformadas y modificadas por las exigencias de un capitalismo que crecía de la mano de la industria y el comercio. 
La transformación económica que vivió Mallorca en el siglo XIX generó unas primeras grietas en aquella pétrea ciudad amurallada. La desamortización y las reformas liberales tuvieron mucho que ver: la Plaza Mayor (1836), la calle de Colón ( 1862), la autorización del primer ensanche en Santa Catalina ( 1869), entre otros, son algunos de los ejemplos del inicio de unas políticas urbanas que persiguieron la producción de ciudad como proceso autopropulsado para la creación de valor y renta urbana. Pero no fue hasta el cambio de siglo, cuando la situación dio la vuelta definitiva con la Ley de cesión y derribos de las murallas (1898) y la aprobación del Plan de ensanche dibujado por Bernat Calvet (1901). Calvet planificó la extensión de la ciudad, hasta entonces amurallada, en una superficie de más de 400 hectáreas que, teóricamente, debían ser suficientes para el crecimiento de la ciudad durante 25 años.

Pero como algunos autores han hecho notar, durante el primer medio siglo XX, el ensanche no despertó el interés de la inversión inmobiliaria que sus valedores proclamaban y esperaban. Así lo decía el sociólogo urbano Luis Carreño en 1965:

el interés del planeamiento de extramuros reflejado por primera vez al Plan de Ensanche Calvet de 1901 queda sustituido durante más de medio siglo por la preocupación de reformas interiores"

Un interés por las reformas interiores que se vieron particularmente reflejadas en el plan redactado por Gabriel Alomar (aprobado en 1943) y, especialmente, en la más importante de estas reformas urbanas: Jaume III. Un proyecto, el de Jaume III, donde el vínculo inmobiliario-financiero ya es muy evidente al ser Juan March quien financió esta operación haussmanniana que se puso en marcha a finales de la década de 1940. La operación de Jaume III venía a significar una especie de ensanche burgués cristalizado intramuros, en el entonces llamado hort d'en Moranta, una operación que habría absorbido gran parte del esfuerzo inversor que los urbanistas esperaban que se focalizase en el ensanche. Se tuvo que esperar a la acumulación de excedentes que la economía turística procuró a los inversores para que la inversión urbana se materializase más allá de las antiguas murallas.

Las reformas urbanas del plan Alomar hicieron saltar algunas alarmas en los sectores más conservadores que, entonces, defendían el patrimonio de la ciudad antigua y la sociedad que la había creado. Así, en 1965 vio la luz la declaración de centro histórico como Conjunto Histórico Artístico que, en parte y muy tímidamente, quería contrapesar las iniciativas de operaciones de sventramento que, más allá de la de Jaume III, proponía el plan Alomar. Las del Puig de Sant Pere y la Calatrava eran planteadas entonces como grandes operaciones que implicaban el desplazamiento de las poblaciones empobrecidas de aquellos barrios por parte de una oferta socio-urbana acomodada que se quería situar en los privilegiados balcones del centro histórico sobre la bahía.

Ya plenamente insertos dentro de la economía turística y las políticas urbanas neoliberales de cuño europeo, en el último tercio del siglo XX y principios del XXI hubo importantes intervenciones en el centro histórico que, de forma generalizada, 
fueron más allá de proyectos puntuales como los mencionados. Tras la aprobación del primer plan general de ordenación urbana (1985) se crearon toda una serie de organismos que han sido los gestores de la transformación del centro: la Gerència d'Urbanisme (1985), el Patronat Municipal de l'Habitatge (1985) y, posteriormente, el Consorci Mirall Palma-Centre. Este último, nacido para desarrollar las operaciones vinculadas a programas europeos, en especial la llamada iniciativa Urban-El Temple (1997-2001) que gestionó actuaciones mixtas a través de partenariados público-privados con importantes inversiones del Urban II.

Los Planes Especiales de Reforma Interior del Puig de Sant Pere (1977), la Calatrava (1989, modificado en 1993), del Jonquet (1985) y de la Gerreria (1995) han terminado de cerrar el círculo para que el centro histórico deje ser definitivamente aquel recinto socialmente diverso de antes de las reformas y pase a ser un espacio más homogéneo socialmente, donde el turismo urbano pueda encontrar su nuevo yacimiento de acumulación después de que el turismo fordista de sol y playa haya agotado sus expectativas de expansión.

Las figuras 4, 5, 6 y 7 permiten observar la expansión de los desahucios en el centro histórico de Palma entre 2003 y 2014. En cuanto las ejecuciones hipotecarias (figuras 6 y 7), estas se concentran especialmente en la parte oriental del antiguo recinto amurallado y, más puntualmente, en el entorno cercano al rehabilitado Puig de Sant Pere, sobre todo en los alrededores de la Llotja. En las dos zonas se localizan áreas de más de 200 desahucios hipotecarios. En cuanto al primero de estos ámbitos, la zona oriental del casco antiguo de Palma, representa el final de una dorsal de un área de desahucios hipotecarios que se enclava en el ensanche oriental. Pero, aunque la topografía hipotecaria parece bien definida y homogénea, no toda la cordillera se explica por el mismo tipo de dinámica. La cuña occidental de esta dorsal, que es más potente en el ensanche, refleja los desahucios y sus correspondientes desplazamientos de población vinculados a uno de los planes de reforma y revitalización mencionados de cuño neoliberal, el de la Gerreria. Se trata, por tanto, del último gran proyecto homogeneizador del centro histórico, la última operación que ha desplazado estratos de población de clase baja para abrir las puertas a la revalorización inmobiliaria como forma de captura de renta urbana.

La topografía de los desahucios por impago de alquiler (figuras 4 y 5) sigue la misma línea dorsal, pero se adentra más en el interior del centro histórico para enlazar con la zona cercana al Puig de Sant Pere/la Llotja. Incluso, este mapa marca un epicentro de más de 1.200 desahucios entre la Plaza Mayor y la calle Sindicat, vinculado a la revitalización comercial denominada la Ruta Martiana, impulsada por el Ayuntamiento y los restauradores de la zona.

Actualmente, se puede afirmar que todo el centro histórico de Palma está inmerso en un proceso de gentrificación pero esta vez no por operaciones puntuales de reforma urbana, sino por un proceso generalizado de turistificación. Desde 2013 la expansión de viviendas vacacionales en el centro histórico está intensificando la transformación de este espacio urbano mediante su revalorización. La expulsión de 
los residentes - por las dificultades de acceder y de encontrar viviendas a un precio asequible- y los cambios de usos - de residencial a turístico- urbanos son los conflictos latentes en este espacio.

En resumen, en el centro histórico de Palma, la proliferación de desahucios descritos forman parte de la dinámica de tres procesos que actúan simultáneamente y que ya ha sido estudiados en otros trabajos: revalorización urbana vinculada a mecanismos de producción de rent gap, embellecimiento urbano y turistización con cambio de usos.

\section{El ensanche}

La segunda de las piezas urbanas de Palma es el ensanche. En sentido amplio, se trata la vasta zona de unas 1.000 hectáreas comprendida entre las Avenidas y la vía de cintura. Planificado inicialmente en 1901 por Calvet y ampliado por Alomar en su plan de 1943, no se consolidó hasta décadas posteriores a su concepción. Tres décadas después de su aprobación, Guillem Forteza criticaba su "suburbialización", proclamando que en el ensanche

no es la ciudad la que ha crecido, sino que ha sido inundada por el suburbio.

En tal afirmación no deja de constatarse una cierta visión clasista, estética y formal de la ciudad que en parte ignora la realidad social. De hecho, Forteza impugna la heterogeneidad de la mezcla social, criticando que

la barraca más rústica alterna con la gran casa de tres o cuatro pisos, la cochera aislada es vecina de un edificio que quiere ser suntuoso, el almacén más modesto forma contraste con el chalet y el jardín idílico, la tienda y el garaje de categoría está delante del hostal antiguo, la casa de confort con ascensor y calefacción central linda con el obrador más insignificante y a veces menos higiénico, los humos de la fábrica se suben en medio del contorno de casas donde juegan los pequeños. El motor y la prensa hidráulica y la caldera de vapor hacen trepidar las paredes medianeras de las habitaciones del estudiante, del enfermo o del jornalero que ha pasado ya todo el día entre correas de transmisión...

Si no se tuvieran en cuenta las cuestiones derivadas de la salubridad, es curioso ver como Forteza criticaba lo que una parte de la urbanística más progresista actual precisamente alaba: la mezcla heterogénea de usos y actividades. En su opinión el ensanche no había servido para aliviar la ciudad antigua, sino que había esparcido sus problemas más allá de las antiguas murallas. De hecho, para Forteza, el ensanche de la década de 1930 era un "amplio polígono de circunvalación" de la ciudad antigua que se formaba junto con el puerto.

Pero este no zonificado y heterogéneo ensanche -desestructurado se diría ahora- que criticaba Guillem Forteza, poco a poco, se zonificó y homogenizó. Se estructuró a lo largo de la segunda mitad del siglo XX en paralelo a su colmatación y urbanización definitiva. Esto se llevó a cabo cuando ya era la acumulación vía economía turística la que directa o indirectamente impulsaba la inversión inmobiliaria también en el ensanche. Pero esta consolidación del ensanche no se hizo con un resultado del todo homogéneo. En otras palabras, la consolidación segregó y dife- 
renció entre un ensanche oriental de clase más baja y un ensanche occidental más acomodada que todavía hoy vemos indirectamente reflejado especialmente en el mapa de ejecuciones hipotecarias (figuras 6 y 7). De aquel grano fino con mezcla de usos que criticaba Forteza, donde el modesto hacía linde con el suntuoso, en la segunda mitad del siglo XX, la articulación había generado una zonificación este-oeste del polígono de circunvalación fortesiano. Los primeros que lo detectaron fueron los urbanistas que analizaban la ciudad en el contexto de la formación de lo que debía ser el PGOU de 1973, el llamado plan Ribas Piera.

En 1965, Luis Carreño, el sociólogo que formó parte del equipo de Ribas Piera, detectaba que sólo parte del ensanche oeste se había estructurado "coherentemente":

el ensanche extramuros sólo consigue atraer el equipamiento escolar (el eje del instituto y Blanquerna). (...) La ciudad burguesa, o bien se articula y se confunde en estrecha solución de continuidad con el centro tradicional (Jaume III), o queda desprovista de una estructura coherente y acabada en las subáreas de Blanquerna y Alexander Fleming.

El mismo Ribas Piera, refiriéndose a 1970, lo exponía con estas palabras:

La conocida "expulsión" de las clases inferiores al extrarradio se cumple en Palma, en 1960, una vez más; pero otros aspectos significativos aparecen también. El sesgo territorial hacia Poniente del estrato más elevado se explica por las diferencias climáticas y de paisaje (...). A "contrario sensu", la concentración de los estratos inferiores en la zona de Levante no sólo es una cuestión de proximidad a terrenos agrarios del municipio y de la isla en general, sino también la cara opuesta de los factores que animan a la localización selectiva en el oeste de la ciudad.

Unas diferencias que, como señalaba Carreño, se hicieron patentes con más intensidad al empezar a consolidarse el ensanche. Mientras al oeste de General Riera se construía una especie de polígono escolar (Instituto Ramon Llull, La Salle, Lluís Vives), en las barriadas más obreras del este (els Hostalets o la Soledat) se localizaban importantes fábricas como la de Can Ribes. Las diferencias entre el ensanche este y el oeste se pueden corroborar y constatar con más detenimiento si analizamos los diferentes indicadores y datos socioeconómicos que el ayuntamiento de Palma ha ido publicando a lo largo de los años.

Los lanzamientos de desahuciados reflejan esta diferencia socio-urbana del ensanche palmesano, pero con matices (figura 8). Las cartografías muestran algunos datos locacionales de los desahucios que hay que analizar con detenimiento. La red de carreteras radiales de Mallorca -centralizada en Palma- se ve reflejada en el trazado viario de la capital. Un modelo radial que se refuerza aún más con otros elementos geográficos como el cauce de la Riera y el trazado de las principales líneas ferroviarias desde las estaciones. Obviando las carreteras costeras, de oeste a este, se localiza la salida hacia Puigpunyent/la Riera, la que conduce a Valldemossa y Sóller que confluye en la calle 31 de Desembre, las líneas de tren, y las calles/carreteras de Inca (Aragó), Manacor y la antigua carretera de Llucmajor (actual calle Foners). Los tres primeros, enclavados en el ensanche centro-occidental, separan claramente di- 
ferentes concentraciones de desahucios. Al oeste de la Riera hay una agrupación de más de 700 ejecuciones hipotecarias en Son Cotoner que, hacia el sur, hacia el Camp d'en Serralta/Santa Catalina, deviene en concentración de más de 1.200 desahucios por impago de alquiler. Entre la Riera y 31 de Desembre/carretera de Valldemossa, en Bons Aires, se detecta una importante concentración de más de 1.000 desahucios de inquilinos y, en el Camp Redó, una de más de 900. En este barrio también se localiza un epicentro de más de 500 ejecuciones hipotecarias en las denominadas viviendas de Corea.

Aunque también hay zonas ubicadas entre la carretera de Sóller y la de Inca (Aragó) donde los desahucios han sido importantes, especialmente en las partes más cercanas a las Avenidas, es entre Aragó y la autopista del aeropuerto donde hay mayor concentración de todo tipo de lanzamientos de desahuciados. Se trata, como se ha apuntado anteriormente, del ensanche oriental, donde la geografía social presenta un estatus social más bajo y un mayor número de desposesiones de vivienda. En este sector las calles/carreteras radiales no interrumpen la topografía de los desahucios. Se trata de un potente macizo con algunos picos destacables que ha pasado por encima de los ejes radiales que mostraban su presencia en el sector centro-occidental. Sin embargo, este gran macizo oriental de desahucios es mucho más agudo al hablar de los hipotecarios, donde la cima del barrio de Son Gotleu destaca por encima del resto, con más de 2.000 ejecuciones hipotecarias. En referencia a los desahucios de inquilinos, la cima de Son Gotleu (de más de 1.200 desahucios) comparte protagonismos con el de Son Canals (de más de 900), Pere Garau (de más de 1.200) y Foners (de más de 900), todos ellos en el ensanche oriental.

\section{Los asentamientos suburbanos periféricos}

Más allá de la vía de cintura -y sin hacer referencia aún a las zonas costeras- se localizan lo que, genéricamente, se ha llamado los asentamientos suburbanos periféricos. Se trata de zonas urbanas de muy diversa génesis pero que, al ubicarse en contacto con el suelo rústico, presentan dos características que las hacen diferentes de la anterior: son espacios menos densos, tanto en cuanto a la edificación como a la demografía, y en donde en los últimos años se han desarrollado promociones suburbanas de nueva construcción alimentadas por la última burbuja inmobiliaria. Estas circunstancias y la presencia de algunas promociones de las décadas de los años 60 y 70 han hecho que, como muestra la figura 8, sean más importantes los lanzamientos por impago hipotecario que por impago de alquileres. En el primer caso hay tres zonas destacadas que, de oeste a este, son Son Roca/Son Ximelis (300 desahucios), Son Cladera/Son Rullan (300 desahucios) y, como continuación de la gran cima de desahucios de Son Gotleu del ensanche, Son Fortesa Nord/el Rafal (230 desahucios). Estas barriadas tienen una destacada representación de promociones públicas de viviendas llevadas a cabo desde la década de 1970 que fueron ocupadas por población de clase baja mayoritariamente inmigrante. El caso de Son Roca/Son Ximelis es paradigmático. Son Roca, un barrio de características rurales que hasta 
mediados del siglo XX también acogía familias de la ciudad histórica que pasaban las vacaciones de verano, se transformó paulatinamente a partir de finales de la década de 1960 y 1970. La inmigración vinculada a la economía ya plenamente turistizada conllevó, entre otras, promociones como la de Son Ximelis donde, entre 1970 y 1975 , se construyeron 1.302 pisos. Una promoción muy vinculada también al polígono industrial de Can Valero, como sucedía también con Son Cladera y la Indioteria con respecto al de Son Castelló. En cuanto a desahucios por impagos de alquiler, aunque se localizan por todos los territorios de estos barrios, destaca particularmente Son Fortesa Nord/el Rafal, con una cima de desahucios de más de 600 desahucios.

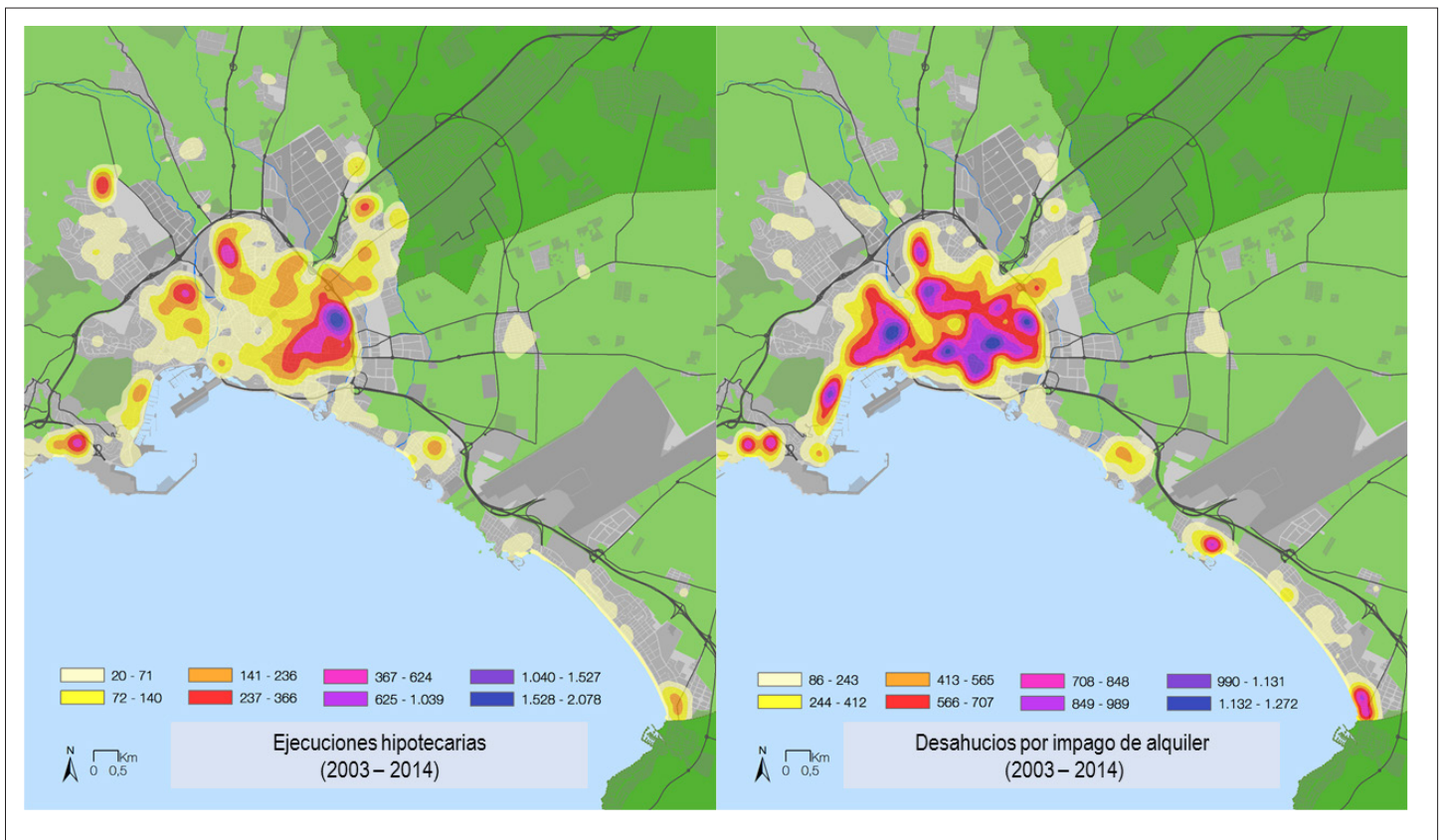

Figura 8: Desahucios en el municipio de Palma Fuente: elaboración propia

\section{Las urbanizaciones costeras}

Las urbanizaciones costeras, en la misma línea de lo que ocurre en el ensanche, presentan una clara diferenciación entre el este y el oeste de la bahía. No obstante, a diferencia de los asentamientos suburbanos periféricos en ellas predominan los lanzamientos por impago de alquiler sobre los hipotecarios (figura 8). La diferente historia urbana de ambos lados de la bahía ayuda a entender estas diferencias. La primera expansión turística costera de Palma fue hacia el actual paseo Marítimo y al oeste de la bahía en dirección a Calvià. Primero fue el Terreno en la década de 1930, reivindicado ya como zona ideal para urbanizaciones de lujo por Guillem Forteza, y que tuvo Cala Major y las zonas turísticas de Calvià como su continuación natural. Por su parte, la parte oriental de la bahía es de desarrollo más tardío y se consolidó plenamente ya en las décadas de 1960 y 1970, cuando el turismo de masas vinculado al sol y playa superó la oferta de las urbanizaciones occidentales con vistas sobre la bahía. Sin embargo, el Molinar y el Coll d'en Rabassa tienen un cierto desarrollo urbano paralelo al Terreno, pero no de población extranjera sino palmesana. 
Sobre este territorio, de cronologías y oferta turístico-residencial similar pero diferente, el mapa de desahucios por impago de alquiler localiza dos zonas importantes a cada lado de la bahía. Al este Can Pastilla y el Arenal, con más de 900 desahucios cada uno, y al oeste el Terreno con más de 1.100 desahucios y Cala Major con más de 900. Estos núcleos son los de mayor concentración de población trabajadora vinculada a las actividades turísticas y de ocio de ambos lados de la bahía. En las urbanizaciones costeras, la geografía de los desahucios hipotecarios es cuantitativamente inferior a la de los de inquilinos (figura 7), aunque su distribución es muy similar. Sin embargo, destaca la cima de Cala Major, con más de 500 desahucios. Se trata de lanzamientos por impago de hipotecas muy vinculados a los apartamentos Pullman-Impala, que ya en la década de 1990 presentaban claros indicadores de empobrecimiento. Es una zona de mucho contraste dado que coexisten importantes áreas residenciales de viviendas unifamiliares y la Fundació Pilar i Joan Miró con una importante bolsa de empobrecimiento capitalizada por los mencionados apartamentos.

Resumidamente se puede apuntar que las cartografías de desahucios se explican, en primer lugar, a la luz de dinámicas y estrategias que se han manifestado a escala global, como el pinchazo de la burbuja financiera. Un pinchazo que en algunos países, como los USA, Irlanda y España, se ha mostrado particularmente destructivo del tejido social y que en el caso de Palma se ha manifestado localmente a partir de los condicionantes geohistóricos como los descritos, los cuales han ido modelando la espacialidad de las relaciones de clase del espacio social de la ciudad.

\section{Conclusiones}

Las cartografías de los desahucios elaboradas a partir de los datos recogidos en el Servicio Común de Notificaciones y Embargos dibujan una geografía desigual del fenómeno de la desposesión de vivienda en Palma. Su evolución muestra la explosión de los desplazamientos a partir del estallido de la burbuja inmobiliaria que afectó a Palma desde finales de los años noventa. Su geografía desigual se puede explicar a partir de la geohistoria de la ciudad, la cual ya se ha ido construyendo con una Palma de clase mediana-alta -la del oeste- y otra Palma de clase trabajadora -la del este-. A partir de este constructo desigual, la articulación de la estrategia de los desahucios se ha establecido sobre él también de manera desigual, manifestándose con mucha mayor intensidad en los barrios históricamente más empobrecidos, especialmente por lo que afecta a las ejecuciones hipotecarias.

No obstante, el análisis cartográfico muestra igualmente otro fenómeno relacionado con la desposesión de vivienda. Los desahucios por impago de alquiler y las ejecuciones hipotecarias son de localización muy diferente. Si bien las ejecuciones hipotecarias están concentradas en los barrios claramente precarizados del este palmesano -Son Gotleu, especialmente-, los desahucios de inquilinos presentan una geografía mucho más difusa con diferentes áreas de concentración. Algunas de las 
más importantes están también en zonas precarizadas, pero se encuentran especialmente concentradas en el centro histórico, Santa Catalina y Bons Aires.

En conclusión, la desigual geografía de los desahucios de Palma se explica mediante las diferentes estrategia espaciales de apropiación de renta a través de los desahucios: en los barrios más empobrecidos predominan las ejecuciones hipotecarias, mientras que en los barrios de clase media se concentran los desahucios de inquilinos en los espacios que se están gentrificando. Una conclusión, sin embargo, conduce a la necesidad de realizar futuras investigaciones que profundicen en las relaciones entre las geografías de clase -y otros privilegios- y los desahucios.

\section{Bibliografía}

AJUNTAMENT DE PALMA. Dades per a un diagnòstic social de la ciutat. Palma: Ajuntament de Palma, 1989.

AJUNTAMENT DE PALMA. Els barris de Palma: revisió del Pla general d'ordenació urbana $i$ d'actuacions urbanístiques. Palma: Promallorca, 1994-95. Ajuntament de Palma, 1998.

ALBERTOS, J. M. y SÁNCHEZ, J. L. (coords.). Geografía de la crisis económica en España. Valencia: Publicacions de la Universitat de València.

ALOMAR, G. Memorias de un urbanista 1939-1979. Palma: Miquel Font editor, 1998.

BAETEN, G., \& LISTERBORN, C. Renewing urban renewal in Landskrona, Sweden: pursuing displacement through housing policies. Geografiska Annaler: Series B, Human Geography, 2015, no 97(3), p. 249-261. http://onlinelibrary.wiley.com/ doi/10.1111/geob.12079/abstract [consulta: 14/01/2018].

BAETEN, G., WESTIN, S., PULL, E., \& MOLINA, I. Pressure and violence: Housing renovation and displacement in Sweden. Environment and Planning A, 2017, n 49(3), p. 631-651. http://journals.sagepub.com/doi/abs/10.1177/0308518X16676271 [consulta: 14/01/2018].

BARCELÓ, B. El Terreno. Geografía urbana de un barrio de Palma. Boletín de la Cámara Oficial de Comercio, Industria y Navegación de Palma de Mallorca, 1963, nº 640, p. 125-178.

CABELLOS, M. La Platja de Palma. Evolució històrica i planejament urbà. Palma: Edicions Documenta Balear, 2016.

CARBONERO, M.A., BALLESTER, LL., HORRACH, A. y SANZ, A. Dades per a un diagnòstic social de la ciutat. Palma. Ajuntament de Palma, 2006.

CARBONERO, M.A., HORRACH, A., MASCARÓ, P. y SANTIAGO, J. L'espai social de l'exclusió a les Balears. Una proposta d'àrees d'atenció preferent. Palma: Caixa de les Balears, 2001.

CARREÑO, L. Estructura social i equipament de Palma de Mallorca. In CLUSA, J. y NEL.LO, O. (eds) Lluís Carreño i Piera (1933-1996). Barcelona. Ajuntament de Barcelona, (1999 [1965]), p. 113-129. 
CRUMP, J. et al. Cities Destroyed (Again) For Cash: Forum on the U.S. Foreclosure Crisis. Urban Geography, 2008, vol. 29, nº 8, p. 745-784. http://www.tandfonline. com/doi/abs/10.2747/0272-3638.29.8.745 [consulta: 14/01/2018].

DOMÍNGUEZ, J., GONZÁLEZ, J.M. i PARREÑO, J.M. Transformaciones recientes en barrios turísticos maduros. Los casos de Palma de Mallorca y Las Palmas de Gran Canaria, España. Scripta Nova. Revista Electrónica de Geografía y Ciencias Sociales. [En línea]. Barcelona: Universitat de Barcelona, l de agosto de 2008, vol. XII, no 270 (93). http://www.ub.es/geocrit/sn/sn-270/sn-270-93.htm [consulta: 14/01/2018].

ERNST \& YOUNG. Impactos sociales y económicos sobre los destinos españoles derivados del exponencial aumento del alquiler de viviendas turísticas de corta duración, impulsado por los nuevos modelos y canales de comercialización P2P. Informe para Exceltur. 2015. http://www.exceltur.org/wp-content/uploads/2015/06/Alojamiento-tur\%C3\%ADstico-en-viviendas-de-alquiler-Impactos-y-retos-asociados.-Informe-completo.-Exceltur.pdf. [Consulta: 24/11/2017].

ESTADA, E. La Ciudad de Palma. Su industria, sus fortificaciones, sus condiciones sanitarias y su ensanche, con apéndice sobre las condiciones que han de reunir las viviendas para ser salubres. Palma: Lleonard Muntaner Editor, 2003[1892].

FIELDS, D. Contesting the financialization of urban space: community organizations and the struggle to preserve affordable rental housing in New York city. Journal of Urban Affairs, 2015, vol. 37, n², p. 144-165. http://www.tandfonline.com/doi/ abs/10.1111/juaf.12098?journalCode=ujua20 [consulta: 14/01/2018].

FIELDS, D. J., RAJKUMAR, K. and SCHAFRAN, A. The emerging economic geography of single-family rental securitization. San Francisco: Federal Reserve Bank, 2016.

FORTEZA, G. Estudis sobre arquitectura i urbanisme. Barcelona: Publicacions de l'Abadia de Montserrat, 1984 [1930].

GARCÍA, J. De la quimera inmobiliaria al colapso financiero. Crónica de un desastre anunciado. Barcelona: Antoni Bosch editor.

GARCÍA? ?AMARCA, M. and KAIKA, M. Mortgaged lives: the biopolitics of debt and housing financialisation. Transactions of the Institute of British Geographers, 2016, $n^{\circ}$ 41.3, p. 313-327. http://onlinelibrary.wiley.com/doi/10.1111/tran.12126/full

GUTIÉRREZ, A. y DECLÓS, X. Geografía de la crisis inmobiliaria en Cataluña: una lectura a partir de los desahucios por ejecución hipotecaria. Scripta Nova. Revista Electrónica de Geografía y Ciencias Sociales]. Barcelona: Universitat de Barcelona, 2017, vol. XXI, no 557. http://revistes.ub.edu/index.php/ScriptaNova/article/ view/17734 [consulta: 14/01/2018].

GUTIÉRREZ, A.; DELCLÒS, X. The uneven distribution of evictions as new evidence of urban inequality: A spatial analysis approach in two Catalan cities. $\mathrm{Ci}$ ties, 2016, no 56, p. 101-108. https://www.sciencedirect.com/science/article/pii/ S0264275116300671 [consulta: 14/01/2018]. 
GUTIERREZ, A.; DOMENECH. A. The Spanish mortgage crisis: Evidence of the concentration of foreclosures in the most deprived neighbourhoods. Die Erde. Journal of the geographical society of Berlin, 2017a, 148 (1), p. 39-57. http://www. die-erde.org/index.php/die-erde/article/view/295 [consulta: 14/01/2018].

GUTIÉRREZ, A; DOMENECH, A. Geografía de los desahucios por ejecución hipotecaria en las ciudades españolas: evidencias a partir de las viviendas propiedad de la SAREB. Revista de Geografía Norte Grande, 2017b, nº 67, p. 33-52. http://www. scielo.cl/scielo.php?script=sci_arttext\&pid=S0718-34022017000200003\&ln$\mathrm{g}=\mathrm{es} \& \mathrm{nrm}=\mathrm{iso}$ [consulta: 14/01/2018].

JANOSCHKA, M., SEQUERA, J., \& SALINAS, L. Gentrification in Spain and Latin America. A critical dialogue. International Journal of Urban and Regional Research, 2014, no 38(4), p. 1234-1265. http://onlinelibrary.wiley.com/doi/10.1111/14682427.12030/abstract [consulta: 14/01/2018].

JANOSCHKA, M. and SEQUERA, J. Gentrification in Latin America: addressing the politics and geographies of displacement. Urban Geography, 2016, no 37.8, p. 1175 1194. http://www.tandfonline.com/doi/abs/10.1080/02723638.2015.1103995?journalCode=rurb20 [consulta: 14/01/2018].

JIMÉNEZ, V.; SÁNCHEZ, J. M. Banca privada y vivienda usada en Madrid. Investigaciones Geográficas, 2016, nº 66, p. 43-58. https://www.investigacionesgeograficas.com/article/view/2016-n66-banca-privada-y-vivienda-usada-en-la-ciudad-de-madrid [consulta: 14/01/2018].

LADARIA, M. D. El ensanche de Palma. Planteamiento del tema, construcción y valoración de un nuevo espacio urbano, 1868-1927. Palma: Ajuntament de Palma, 1992.

MAHARAWAL, M. M. Black Lives Matter, gentrification and the security state in the San Francisco Bay Area. Anthropological Theory, 2017, n 17(3), p. 338-364. http://journals.sagepub.com/doi/abs/10.1177/1463499617732501 [consulta: 14/01/2018].

MAYOL, J. L'arquitectura escola de Guillem Forteza Pinya. Societat, cultura i politica a la Mallorca de començament del segle XX. Palma: Lleonard Muntaner Editor, 2011.

MÉNDEZ, R. De la hipoteca al desahucio: ejecuciones hipotecarias y vulnerabilidad territorial en España. Revista de Geografía Norte Grande, 2017, $\mathrm{n}^{0}$ 67, p. 9-31. http://www.scielo.cl/scielo.php?script=sci_arttext\&pi$\mathrm{d}=$ S07 18-34022017000200002\&lng=pt\&nrm=iso [consulta: 14/01/2018].

MÉNDEZ, R., ABAD, L. y PLAZA, J. Geografía de las ejecuciones hipotecàrias en España. Madrid: Fundación 1 de mayo, 2014. http://www.lmayo.ccoo.es/nova/files/1018/Estudio84.pdf [consulta: 26/11/2017].

MÉNDEZ, R.; PLAZA, J. Crisis inmobiliaria y desahucios hipotecarios en España: una perspectiva Geográfica. Boletín de la Asociación de Geógrafos Españoles, 2016, no 71, p. 99-127. http://mov-brs-0 l.aragon.es/cgi-bin/IDOT/BRSCGI?CMD=VEROBJ\&MLKOB=931 178403948 [consulta: 14/01/2018]. 
MOORE, M.; RODRÍGUEZ-VIVES, M. y SACA-SACA, N. N. Mortgage Markets and Foreclosure Processes in Europe and the United States. In Enoch, C. et al. From Fragmentation to Financial Integration in Europe, Washington D.C.: International Monetary Fund, 2013, 409-432.

OBESO, Í. Análisis geográfico de los desahucios en España. Ería, 2014, no 95, p. 327 342. https://www.unioviedo.es/reunido/index.php/RCG/article/view/10513 [consulta: 24/11/2017].

PARCERISA, J. Forma Urbis. Cinco ciudades bajo sospecha. Barcelona: Universitat Politècnica de Barcelona, 2012.

PURSER, G. The circle of dispossession: Evicting the urban poor in Baltimore. Critical Sociology, 2016, no 42(3), p. 393-415. http://journals.sagepub.com/doi/ abs/10.1177/0896920514524606 [consulta: 14/01/2018].

RAYA, J. M. The determinants of foreclosures: Evidence from the Spanish case. $\mathrm{Pa}$ pers in Regional Science. 2017, Early view: doi:10.1111/pirs.12316. http://onlinelibrary.wiley.com/doi/10.1111/pirs.12316/abstract [consulta: 14/01/2018].

RIBAS, M. Palma de Mallorca, 1970: un claro ejemplo de estructura radiocéntrica. Revista de la Universidad Complutense, 1979, n 115, p. 143-168.

RUIZ, C. L'urbanisme de la Ciutat de Palma. Palma: Editorial El Far, 2000.

STENBERG, S., DOORN, L. y GERULL, S. Locked out in Europe: A Comparative Analysis of Evictions Due to Rent Arrears in Germany, the Netherlands and Sweden. European Journal of Homelessness, 201 1, vol. 5, no 2, p. 39-61. https://www.researchgate.net/publication/267203599_Locked_out_in_Europe_A_Comparative_Analysis_of_Evictions_Due_to_Rent_Arrears_in_Germany_the_Netherlands_and_Sweden [consulta: 14/01/2018].

VIVES-MIRÓ, S. L'espai urbà del capitalisme. La construcción del projecte neoliberal de Palma. Palma: Universitat de les Illes Balears, 2012.

VIVES-MIRÓ, S. y RULLAN, O. Capturing urban rent through evictions: home dispossessions in the historic centre of Palma (Majorca). In Gentrification as a Global Strategy. Neil Smith and Beyond. New York: Routledge, 2017a, p. 152-162.

VIVES-MIRÓ, S. y RULLAN, O. Espacio, clase y desplazamientos. Ampliando la diferenciación de clase a través de los desahucios, In Actas del XXV Congreso de la Asociación de Geógrafos Españoles "Naturaleza, Territorio y Ciudad en un Mundo Global". Madrid. Asociación de Geógrafos Españoles, 2017b, p. 2359-2366. https://doi.org/10.15366/ntc.2017 [consulta: 24/11/2017].

VIVES-MIRÓ, S. y RULLAN, O. Desposesión de vivienda por turistización? Revalorización y desplazamientos en el Centro Histórico de Palma (Mallorca). Revista de Geografía Norte Grande, 2017c, n 67, p. 53-71. http://www.scielo.cl/pdf/rgeong/ n67/art04.pdf [consulta: 24/11/2017]. 
VIVES-MIRÓ, S. y RULLAN, O. Financiarization and privatization of the built environment in the urban dynamic post-crisis. Comunicación en la sesion Geography of Financial Markets, Institution and Centers. The fianciarization of City-making: Articulation critical perspectives. Chicago: IL Annual Meeting of the Association of American Geographers, 2015.

VIVES-MIRÓ, S., RULLAN, O. y GONZÁLEZ, J. M. Geografies de la despossessió d'habitatge a través de la crisi. Els desnonaments de marca Palma/ Geografías de la desposesión de vivienda a través de la crisis. Los desahucios Marca Palma/ Understanding geographies of home dispossession through the crisis. Evictions Palma Style. Barcelona: Icaria Editorial, 2018.

VIVES-MIRÓ, S.; RULLAN, O. González, J. Consecuencias sociales del modelo económico basado en el crédito. Geografía de las ejecuciones hipotecarias en Menorca. Scripta Nova. Revista Electrónica de Geografía y Ciencias Sociales, 2017, vol. 21 , $\mathrm{n}^{\circ}$ 553. http://revistes.ub.edu/index.php/ScriptaNova/article/view/553 [consulta: 14/01/2018].

VIVES-MIRÓ, S.; RULLAN, O.; GONZÁLEZ, J. Home dispossession: the uneven geography of evictions in Palma (Majorca). Die Erde. Journal of the geographical society of Berlin, 2015, $\mathrm{n}^{\circ} 146$ (2-3), p. 113-126. http://www.die-erde.org/index. $\mathrm{php} /$ die-erde/article/view/211 [consulta: 14/01/2018].

(c) Copyright: SÒNIA VIVES-MIRÓ, ONOFRE RULLÁN, JESUS M. GONZÁLEZ PÉREZ, 2018

(c) Copyright Scripta Nova, 2018.

Ficha bibliográfica:

VIVES-MIRÓ, Sònia; RULLÁN, Onofre; GONZÁLEZ PÉREZ, Jesús M. Cartografías de los desplazamientos por desposesión de vivienda. Desahucios y ejecuciones hipotecarias en Palma a través de su geohistoria, Scripta Nova. Revista Electrónica de Geografía y Ciencias Sociales. [En línea]. Barcelona: Universidad de Barcelona, 1 de junio de 2018, vol. XXII, nº 591. ISSN: $1138-9788$. 
